\title{
PREVALENCE AND ASSOCIATED FACTORS OF UNDER- NUTRITION AMONG UNDER-FIVE CHILDREN OF BHARATPUR MUNICIPALITY OF CHITWAN DISTRICT, NEPAL
}

\author{
Pokhrel $A U^{1 *}$, Parajuli $S B^{2}$, Acharya $A^{1}$
}

\section{Affiliation}

1. Lecturer, Nobel Medical College Teaching Hospital, Biratnagar, Morang, Nepal

2. Lecturer, Birat Medical College \& Teaching Hospital, Biratnagar, Morang, Nepal

\section{ARTICLE INFO}

\section{Article History}

Received : 13 October, 2017

Accepted : 25 October, 2017

Published : 31 December, 2017

(c) Authors retain copyright and grant the journal right of first publication with the work simultaneously licensed under Creative Commons Attribution License CC - BY 4.0 that allows others to share the work with an acknowledgment of the work's authorship and initial publication in this journal.

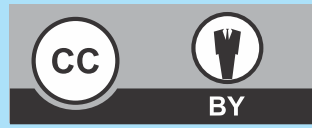

ORA 41

DOI: http://dx.doi.org/10.3126/bjhs.v2i3.18941

\section{* Corresponding Author \\ Dr. Ava Upadhyay Pokhrel Lecturer}

Department of Community Medicine Nobel Medical College Teaching Hospital, Biratnagar

Email: avapokhrel01@hotmail.com

\section{Citation}

Pokhrel AU, Parajuli SB, Acharya A. Prevalence and Associated Factors of Under-nutrition Among Under-five Children of Bharatpur Municipality of Chitwan District, Nepal BJHS 2017;2(3)4:266-272

\section{ABSTRACT}

\section{Introduction}

Under-nutrition during childhood, a major public health problem of Nepal, can have everlasting consequences. It is one of the primary causes of ill health and premature deaths in many developing countries like Nepal.

\section{Objective}

The objective of the study was to assess the prevalence and associated factors of under-nutrition among under-five children of Bharatpur municipality of Chitwan district of central Nepal.

\section{Methodology}

A cross sectional study was conducted in Bharatpur municipality of Chitwan district. Anthropometric measurement of children and information regarding nutrition along with different exposures were taken from 402 randomly sampled mothers. WHO criteria was used to compare with the calculated Z-score using Anthro V3.2.2 software. Informed consent was taken from concerned authority. Descriptive statistics were calculated and binary logistic regressions was used to determine the influence of selected variables for underweight.

\section{Results}

Majority of the respondents were from relatively advantaged groups and house makers. Almost $54 \%$ of the children were boys and the greatest share of children was of age group 25-36 months. Almost one in 10 children of Bharatpur had lower weight-for-height score (wasted). Likewise, more than one quarter (26.4\%) were stunted and another $13.4 \%$ were under-weight. Families with less than four family members were less likely to have under-weight children and those who had more than two children had more chance of having under-weight children $(P=0.002)$. Children having diarrheal episodes within 2 weeks period of study had higher odds of being malnourished.

\section{Conclusion}

The study shows that female children have higher risks of being malnourished. Higher prevalence of underweight was seen with the increasing age of children. The size of family also matters the nutrition status of children. It is recommended that Ministry of Health needs to have more attention for the necessary intervention addressing the combined exposures factors for underweight.

\section{KEYWORDS}

Child, Nepal, nutritional status, prevalence 


\section{INTRODUCTION}

Nutritional status of children is very important as it determines their health, physical growth and development of children including academic performance and progress in life. All children have the right to acquire adequate nutrition, which is essential for attainment of the highest standard of health. ${ }^{1}$ Moreover, a good nutrition has been reported to be the corner stone for survival, health and development in the current and succeeding generations. ${ }^{2}$ Unfortunately, the crucial period of life childhood is often burdened with protein-energy and micronutrient inadequacies that lead to lagging optimal growth and development. ${ }^{3}$ Deficiency of micro or macronutrients may initiate the episode of malnutrition. Malnutrition may present in different forms ranging from acute deficiencies to grave and long lasting chronic conditions. The most widely prevailing forms of malnutrition are protein-energy malnutrition (PEM) and micronutrient deficiencies. PEM comprise of stunting, under-weight and wasting. The major burden of malnutrition has been concentrated in specific groups such as children and women, which pose great threat to socio-economic situation of families and the nation. ${ }^{4}$ Malnutrition during childhood is correlated to under development of children's intellect and causes learning impairment. The effects of malnutrition on human performance, health and survival have been the subject of extensive research for several decades and studies show that malnutrition affects physical growth, morbidity, mortality, cognitive development, reproduction, and physical work capacity. ${ }^{5}$ Malnutrition is an underlying factor in many diseases in children, and it contributes greatly to the disability-adjusted life years worldwide. ${ }^{6}$ Several indicators of Millennium Development Goals (MDGs) are directed towards nutrition directly or in an indirect path. It has been well accepted that improvement in nutritional status of children and women can help achieve many of the MDGs. ${ }^{4}$

Currently, around 925 million people worldwide suffer from long term hunger i.e. they have no access to enough nutritious food for a healthy life; the worst is being those living in under developed countries. Among children in developing countries, malnutrition is an important factor contributing to illness and death. Malnutrition during childhood can also affect growth potential and the risk of morbidity and mortality in later years of life. Malnutrition among children is rampant among the South Asian Countries. About half of all children deaths are associated with malnutrition of which three quarters are liked to mild and moderate forms.$^{7.8}$ In 2005, in all developing countries $32 \%$ of children under 5 years of age (178 million children) were estimated to be stunted. In that year, more than $40 \%$ of stunting was found in regions of Africa and South- East Asia. The global estimate of wasting occurring among children less than 5 years of age based on WHO new standard is $10 \%$ (or 55 million). The highest numbers of affected children, 29 million are estimated to live in SouthCentral Asia. ${ }^{9}$ In 2007 , an estimated $26 \%$ of children underfive years of age in developing countries were under weight, out of 112 million children. Under-weight is most common in regions of Asia (48\%), followed by Sub-Saharan Africa (28\%). ${ }^{7}$ There is wide variation in the state of malnutrition throughout Nepal. Stunting (41\%) is more common in mountain areas than in the Terai, but underweight $(29 \%)$ and wasting (11\%) are more common in the Terai than in the mountain areas. ${ }^{3}$

Malnutrition has been widely accepted as a serious threat to child survival and overall physical and mental development. The worst hit areas of the problem are the developing countries. The most common forms of malnutrition i.e. PEM and micronutrient deficiencies are widely prevalent in Nepal. PEM is considered a major public health problem in Nepal which is considered to be the outcome of several factors such as household food insecurity, poor nutritional intake, frequent attacks of infectious diseases and sanitation related factors. Several studies conducted in Nepal have found out different risk factors associated with child under nutrition. A great variation is observed among children on the basis of their residence and topography. Malnutrition places the child to greater risk of dying from common childhood illness as compared to those adequately nourished. ${ }^{7}$ Various risk factors are considered to be responsible for the nutrition status of children. Maternal factors such as education and occupation have shown association with status of child nutrition. Service access and utilization on the other hand are crucial determinants for child nutrition. Stunting is a chronic condition with mostly irreversible effects that usually occurs before the child reaches the age of two years. The effects include decreased development of mental abilities including learning problem and delayed motor development. Wasting on the other hand is an acute condition resultant of noticeable weight loss due to an infection or inadequate dietary intake. ${ }^{10}$

Some factors identified by a very few or nominal studies have been conducted to address the real scenario of urban area undernutrition. Bharatpur municipality is in the process of rapid urbanization. Thus, this study aimed to assess the prevalence and different associated factors with under-nutrition among under-five children of Bharatpur municipality of Chitwan district of central Nepal.

\section{METHODOLOGY}

This is a cross-sectional study carried out at Bharatpur municipality of Chitwan district. Bharatpur municipality, a headquarter of Chitwan district, is situated in the western part of Narayani Zone, Nepal. It covers an area of 2,218 $\mathrm{Km}^{2}$ and consisted of a population of 579,984. Bharatpur municipality consists of 14 wards. The municipality is resided by heterogeneous group of people with multi ethnicities. The target population of the study was underfive children of the Bharatpur municipality. A sample size of 420 was derived on the basis of prevalence of stunting under-five children being $49 \%$, allowable error $5 \%$ of prevalence of stunted and adding $5 \%$ for non-responses. ${ }^{8}$ 
Regarding the sampling technique, each ward of the municipality was considered a stratum. List of the household with study population was obtained from municipality. Stratified simple random sampling technique with equal allocation method was applied. From each ward 30 children under-five years were selected randomly. With help of Village Health Workers (VHW), children under-five years were identified. Out of 420 samples, six respondents refused to take part in the study and 12 houses found closed even in second attempts. Semi structure questionnaire was used to interview the mothers and observations were done to measure weight, height and MUAC (Mid Upper Arm Circumference) of children using weighing machine and measuring tape.

Data processing and analysis: Data was entered into Microsoft Office Excel 2007 and analysis was done in Statistical Package for Social Science (17.0). Anthropometric data were transferred to "Anthro V3.2.2" program for further analysis. Socio-demographic information of mother and child were categorized and anthropometric variables of child were recorded. Anthropometric variables were further processed and categorized based on CDC/WHO (1978) classification.

Under-weight, stunting and wasting were categorized using information regarding weight-for-age, height-forage, weight-for-height as per need during analysis. Severe and moderate stunting, under-weight and wasting were mainly categorized as undernourished: if z-score was less than -2 SD and not undernourished: if z-score was more than -2 SD. Similarly, under-weight and normal were categorized with cut of value of 2 SD z-score. Chi-square test was used for bivariate analysis. Binary logistic regression analysis for under-weight was applied using enter method approach to find out adjusted significant predictors. Probability of significance was determined at $5 \%$ level.

Validity and reliability: The weighing machine was calibrated before measuring weight of each respondent. Every anthropometric measurement of the child was measured twice and ensured the correct measurements, reading and recordings. Cross-questions were asked to each mother to verify the responses and enough time was provided to remember to minimize recall bias especially for the memories based information. Questionnaire was translated into Nepali language and checked by an expert. The original and new versions of questionnaire were compared for exactness and necessary modification was done. Pre-testing was done in similar community and validity of the tools in its contents and accuracy of information was ensured. The filled questionnaires were checked in end of each day. The data was entered into computer and every 20 entry crosscheck was done.

Ethical clearance was obtained from concerned authority of college. Consent was taken with the participants before interview and objectives of the study were clarified. Participants were assured that the information they provide would maintain privacy and confidentially.
Operational definition: Acute Respiratory Infection (ARI): This includes cough, cold, chest pain with and without fever. The episode was taken for the period of two weeks preceding the study.

Minimum dietary diversity: It includes seven groups of food such as 1) grains, root, and tubers 2) legumes and nuts 3) dairy products 4) meet and meet products 5) eggs 6) vitamin A rich fruits and vegetables 7 ) other fruits and vegetables. The cutoff of at least four of the above seven food groups was selected.

Exclusive breast-feeding: Breast-feeding practice in which infant or child only received breast milk from mother without any additional food or drink. It allows oral rehydration solution, drops and syrups. It did not include children who receive pre-lacteal.

Complementary feeding: It is the introduction of additional food to children other than breast milk in 180 days of childbirth.

Childhood diseases: It included diarrhoeal disease and ARI. Immunization status: It was categorized as completed and not completed. Those children who received measles vaccine were considered to have completed immunization.

Economic status: It is based on Kuppuswamy's Socioeconomic Status scale, a composite indicator on the basis of education, monthly average income and occupation.

Nutritional status: It is considered based on the prevalence of stunting, under-weight and wasting by using anthropometric measurements. Gradation of malnutrition was categorized by Z- value of reference median population as outlined by the World Health Organization (WHO) using its software "Anthro" (V3.2.2).

Wasting: Anthropometric index weight-for-height reflects the body weight of a child relative to his/her height. Wasting refers to low weight-for-age at $<-2$ SD of the median value of the WHO reference.

Under weight: Anthropometric index for weight-for-age, which represents the body mass in relative to the age of the children. Under-weight refers to a deficit and is defined as low weight-for-age at <-2SD.

Stunting: Stunting or shortness in height refers to low height-for-age that may reflect either normal variation in growth or a deficit in growth. It is defined as low height-forage at $<-2$ SD of the median reference value.

\section{RESULTS}

The socio-demographic characteristics of study participants were given in table 1 . More than half of the respondents were Brahmin and Chhetri (57.2\%), followed by Janajati (28\%) and Dalit (14\%). Majority (89.6\%) of them were Hindu. Maximum (80.6\%) of the children were living in the family with two or less children. More than $42 \%$ of the children were living in nuclear family. Almost two third of the under-five children were living in family size of 1-4. More 
than $61 \%$ of the children live in family having no land for farming. Moreover, among those who had their own land, $24 \%$ of the family had agricultural product enough for only six month. According to modified Kuppuswamy's socioeconomic status, more than half of the participants were at upper middle class.

\section{Table1: Socio-demographic characteristics of study} participants ( $n=402)$

\begin{tabular}{|c|c|c|}
\hline Characteristics & Number & Percent \\
\hline \multicolumn{3}{|l|}{ Ethnicity } \\
\hline Brahmin & 158 & 39.3 \\
\hline Chhetri & 72 & 17.9 \\
\hline Janajati & 111 & 27.6 \\
\hline Dalit & 56 & 13.9 \\
\hline Other & 5 & 1.3 \\
\hline \multicolumn{3}{|l|}{ Religion } \\
\hline Hindu & 360 & 89.6 \\
\hline Christian & 13 & 3.2 \\
\hline Buddhist & 24 & 6.0 \\
\hline Muslim & 5 & 1.2 \\
\hline \multicolumn{3}{|l|}{ Family type } \\
\hline Nuclear & 170 & 42.3 \\
\hline Joint & 222 & 55.2 \\
\hline Extended & 10 & 2.5 \\
\hline \multicolumn{3}{|l|}{ Family size } \\
\hline 1-4 members & 265 & 65.9 \\
\hline 5 and more members & 137 & 34.1 \\
\hline Mean family size & \multicolumn{2}{|c|}{$5.18 \pm 1.923$} \\
\hline \multicolumn{3}{|c|}{ Number of children in the family } \\
\hline 2 or less & 324 & 80.6 \\
\hline 3 or more & 78 & 19.4 \\
\hline \multicolumn{3}{|l|}{ Farming land possession } \\
\hline Yes & 154 & 38.3 \\
\hline No & 248 & 61.7 \\
\hline \multicolumn{3}{|c|}{ Sufficiency of food from own farm land } \\
\hline$\leq 3$ months & 8 & 5.2 \\
\hline 4-6 months & 29 & 18.8 \\
\hline More than 6 months & 117 & 76.0 \\
\hline \multicolumn{3}{|l|}{ Socio-economic status* } \\
\hline Lower & 11 & 2.7 \\
\hline Lower upper lower & 82 & 20.4 \\
\hline Middle lower middle & 55 & 13.7 \\
\hline Upper middle & 216 & 53.7 \\
\hline Upper & 38 & 9.5 \\
\hline
\end{tabular}

*Modified Kuppuswamy's socioeconomic status scale ${ }^{11}$

Table 2 shows the maternal characteristics of study participants. Majority (80.7\%) were currently living together. Only $35.8 \%$ of the under-five children were reared by the mother with academic attainment of higher secondary level. Majority (90.3\%) of the under-five children were born when their mothers were of age 20 to 35 years while $6.7 \%$ born when their mothers were in teen age. Few mothers $(4.5 \%)$ smoked during pregnancy and $4 \%$ were continuing smoking.

\begin{tabular}{|c|c|c|}
\hline Maternal Characteristics & Number & Percent \\
\hline \multicolumn{3}{|l|}{ Marital status } \\
\hline Together & 324 & 80.7 \\
\hline Separate & 3 & 0.7 \\
\hline Divorce & 2 & 0.5 \\
\hline Widowed & 1 & 0.2 \\
\hline Foreign employed & 72 & 17.9 \\
\hline \multicolumn{3}{|l|}{ Educational status } \\
\hline Informal education & 6 & 1.5 \\
\hline Primary & 43 & 10.7 \\
\hline Lower secondary & 70 & 17.4 \\
\hline Secondary & 112 & 27.9 \\
\hline Higher secondary & 144 & 35.8 \\
\hline Illiterate & 27 & 6.7 \\
\hline \multicolumn{3}{|l|}{ Occupational status } \\
\hline Agriculture & 42 & 10.4 \\
\hline Labor & 14 & 3.5 \\
\hline Service & 80 & 19.9 \\
\hline Business & 27 & 6.7 \\
\hline House maker & 239 & 59.5 \\
\hline \multicolumn{3}{|l|}{ Smoking during pregnancy } \\
\hline Yes & 18 & 4.5 \\
\hline No & 384 & 95.5 \\
\hline \multicolumn{3}{|l|}{ Current smokers } \\
\hline Yes & 16 & 4.0 \\
\hline No & 386 & 96.0 \\
\hline \multicolumn{3}{|c|}{ Mother age at the child birth(years) } \\
\hline Less than 20 & 27 & 6.7 \\
\hline $20-35$ & 363 & 90.3 \\
\hline More than 35 & 12 & 3.0 \\
\hline
\end{tabular}

Table 3 demonstrates child characteristics of study participants. The mean age of the children was 25.95 months with SD 15.32 months. Among them, infants comprised almost $24 \%$ of under-five population. Male children were more than female. Twenty four percent of children had fever followed by diarrhea (13.4\%) within last 2 weeks of study. Majority (98.4\%) had Measles immunization among child aged $>12$ months.



Only $6.2 \%$ of the study children were exclusively breast feed. However, ideal age of weaning is 5-6 months, $8 \%$ of children 
were weaned at the age of 7 or more than 7 months. Study revealed that majority of the children's diet of last 24 hours consist of grain roots/tubes and legumes nut $(96.6 \%$ and 95.2\%) respectively (Table 4).

\begin{tabular}{|c|c|c|}
\hline Feeding practices & Number & Percent \\
\hline \multicolumn{3}{|l|}{ Current feeding practices } \\
\hline Exclusive breast feeding & 25 & 6.2 \\
\hline Complementary feeding & 252 & 62.7 \\
\hline Other food only & 125 & 31.1 \\
\hline \multicolumn{3}{|l|}{ Age of weaning $(n=377)$} \\
\hline 6 months or less & 350 & 92.8 \\
\hline 7 months or more & 27 & 8.2 \\
\hline \multicolumn{3}{|l|}{$\begin{array}{l}\text { Food diversification within } 24 \\
\text { hours }(n=377)\end{array}$} \\
\hline Grain roots and tubers & 364 & 96.6 \\
\hline Legumes and nuts & 359 & 95.2 \\
\hline Dairy products & 275 & 72.9 \\
\hline Meat and fish & 98 & 26.0 \\
\hline Eggs & 103 & 27.3 \\
\hline Vitamin A fruits and vegetables & 232 & 61.5 \\
\hline Other fruits and vegetables & 195 & 51.7 \\
\hline
\end{tabular}

Figure 1 demonstrates malnutrition status of under-five children. Out of the total 402 children, almost one in ten (9.7\%) were wasted i.e. weight-for-height Z-score less than 2 standard deviation. Likewise, more than one quarter (26.4\%) were stunted and another $13.4 \%$ were underweight. The average Z-score for weight-for-height in relation to the age of child lies below zero except for the age group 36-47 months. Alike weight-for-height, the average Z-score for height-for-age is below zero expect for the age group 0-6 months. Unlike these two variables, no age group has an average Z-score value more than zero for weight-for age.

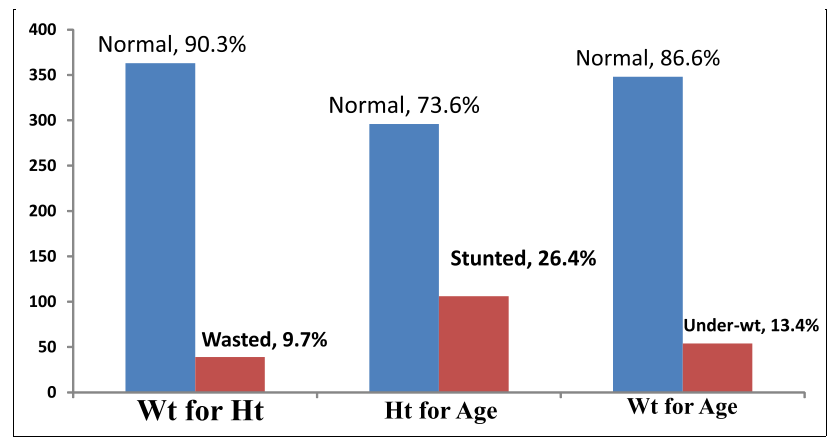

Figure 1: Malnutritions tatus of under-five children $(n=402)$

\section{Table 5: Adjusted factors associated with under-weight among under-five children ( $\mathrm{n=402}$ )}

\begin{tabular}{|c|c|c|c|c|}
\hline Characteristics & $\begin{array}{c}\text { Under weight } \\
\text { n (\%) }\end{array}$ & $\begin{array}{c}\text { Normal } \\
\text { n (\%) }\end{array}$ & OR $(95 \% \mathrm{Cl})$ & \\
\hline $\begin{array}{l}\text { Ethnicity } \\
\text { Brahmin and Kshetri }\end{array}$ & $32(59.3 \%)$ & 198(56.9\%) & Reference & \\
\hline Janajati & $11(20.4 \%)$ & $100(28.7 \%)$ & $1.13(0.40,3.25)$ & \\
\hline Dalit and others & $11(20.4 \%)$ & $50(14.4 \%)$ & $0.51(0.17,1.54)$ & \\
\hline \multicolumn{5}{|l|}{ Type of family } \\
\hline Nuclear & $27(50.0 \%)$ & $143(41.1 \%)$ & Reference & \\
\hline Joint and Extended & $27(50.0 \%)$ & $205(58.9 \%)$ & $2.40(0.98,5.88)$ & 0.055 \\
\hline \multicolumn{5}{|l|}{ Total family members } \\
\hline 5 or more & $26(48.1 \%)$ & $237(68.1 \%)$ & Reference & \\
\hline Less than 5 & $28(51.9 \%)$ & $111(31.9 \%)$ & $0.30(0.12,0.73)$ & 0.008 \\
\hline \multicolumn{5}{|l|}{ Total children in house } \\
\hline 3 or more & $24(44.4 \%)$ & $294(84.5 \%)$ & Reference & \\
\hline 2 or less & $30(55.6 \%)$ & $54(15.5 \%)$ & $0.32(0.16,0.66)$ & 0.002 \\
\hline \multicolumn{5}{|l|}{ Economic status } \\
\hline Lower & $11(20.4 \%)$ & $82(23.5 \%)$ & Reference & \\
\hline Middle & $39(72.2 \%)$ & $232(66.7 \%)$ & $0.85(0.20,3.54)$ & 0.819 \\
\hline Upper & $4(7.4 \%)$ & $34(9.8 \%)$ & $1.12(0.34,3.69)$ & 0.850 \\
\hline \multicolumn{5}{|l|}{ Education status of mother } \\
\hline Illiterate & $6(11.1 \%)$ & $21(6.0 \%)$ & $1.50(0.40,5.59)$ & 0.632 \\
\hline Up to lower secondary & $21(38.9 \%)$ & $98(28.2 \%)$ & $1.44(0.67,3.11)$ & 0.547 \\
\hline Secondary and above & $27(50.0 \%)$ & $229(65.8 \%)$ & Reference & \\
\hline \multicolumn{5}{|l|}{ Occupation of mother } \\
\hline Agriculture & $4(7.4 \%)$ & $38(10.9 \%)$ & Reference & \\
\hline Labor/service/ business & $13(24.1 \%)$ & $108(31.0 \%)$ & $0.43(0.12,1.58)$ & 0.205 \\
\hline Homemaker & $37(68.5 \%)$ & $202(58.1 \%)$ & $0.54(0.24,1.19)$ & 0.126 \\
\hline \multicolumn{5}{|l|}{ Age of mother at birth } \\
\hline Less than 20 and more than 35 & $7(13.0 \%)$ & $32(9.2 \%)$ & Reference & \\
\hline 20-35 years & $47(87.0 \%)$ & $316(90.8 \%)$ & $0.69(0.25,1.91)$ & 0.470 \\
\hline \multicolumn{5}{|l|}{ Smoking during pregnancy } \\
\hline No & $50(92.6 \%)$ & $334(96.0 \%)$ & Reference & \\
\hline Yes & $4(7.4 \%)$ & $14(4.0 \%)$ & $1.08(0.23,5.11)$ & 0.924 \\
\hline \multicolumn{5}{|l|}{ Sex of the child } \\
\hline Male & $29(53.7 \%)$ & $186(53.4 \%)$ & Reference & \\
\hline Female & $25(46.3 \%)$ & $162(46.6 \%)$ & $0.90(0.46,1.74)$ & 0.749 \\
\hline \multicolumn{5}{|l|}{ Age group of child } \\
\hline $0-11$ months & $10(18.5 \%)$ & $86(24.7 \%)$ & Reference & \\
\hline $13-35$ months & $28(51.9 \%)$ & $188(54.0 \%)$ & $0.64(0.23,1.79)$ & 0.389 \\
\hline $36-59$ months & $16(29.6 \%)$ & $74(21.3 \%)$ & $0.83(0.39,1.79)$ & 0.640 \\
\hline \multicolumn{5}{|l|}{ Illness since last 2 weeks } \\
\hline Fever & $11(20.4 \%)$ & $86(67.1 \%)$ & Reference & \\
\hline Diarrhea & $12(22.2 \%)$ & $42(32.9 \%)$ & $2.06(0.88,4.79)$ & 0.095 \\
\hline
\end{tabular}


Binary logistic regression with enter strategy was used to find out association of under-weight with other independent variables. Few variables were merged for the convenience and applicability of the tests. Table 5 illustrates ethnicity has no significant association with under-weight of children. Children from joint or extended families were 2 times more likely to be under-weight as compare to the Nuclear family $(\mathrm{OR}=2.4,95 \% \mathrm{Cl}=0.98-5.88)$. Size of family members was statistically significant with weight of the children $(P=0.008, O R=0.3,95 \% \mathrm{Cl}=0.12-0.73)$; families with less than 4 family members were at less risk against underweight in comparison to 5 or more family size. Similarly, families with two or less children had less chance of having under-weight children $(\mathrm{P}=0.002, \mathrm{OR}=0.32,95 \% \mathrm{Cl}=0.16$ 0.66). Children from middle economic classes had better status of weight-for-age as compared to their counter part from upper or lower economic classes. Under-weight seemed to have increased odds with the increase in educational status of the mother. Age of mother between 20-35 years was found protective against under-nutrition of their children. Mother who smoked during pregnancy had seven percent higher chance of having under-weight babies. Sex was not a significant predictor of under-weight.

\section{DISCUSSION}

Nutrition is backbone of health of individual of any nation. However, nutrition problem may be with the whole population, children and women are the most at risk group from malnutrition. Appropriate and adequate nutrition is an important prerequisite for the normal development of a child. In this study, nutritional status of children was assessed based on three different indicators like stunting, wasting and under-weight. Age and anthropometric values such as height and weight of the study children were obtained and evaluated on the basis of the standard WHO Z-score. The cut off point for identification of malnourished children was minus two standard deviation (-2SD). In this study, highest proportion of children were of age group 25-36 months (28.1\%) followed by $13-24$ months (25.6\%) and $0-12$ months (23.9\%). The mean age of children was 25.95 months with SD of 15.32. Male female ratio was 1.15:1.0. The study somehow shows varied data as compared to other national or small scale researches conducted. Almost 1 in 10 children in the study area were wasted which is similar to finding of NDHS 2011. ${ }^{3}$ The finding is much less compared to the study carried out in Bhawaniyapur VDC of Banke district where $17.3 \%$ and in Bardiya more than $16 \%$ of children were wasted. ${ }^{12-14}$

The prevalence rate of wasting is more in the study area than the national data for urban areas (8.2\%) but it is less than the ecological region (11.2\%) and development region $(11.6 \%)$ where the study area is located. More than $11 \%$ of boy were wasted compared to $8 \%$ of girls which is similar to national figure of $12 \%$ and $9.7 \%$ for boys and girls respectively. ${ }^{3}$ It coincides with the trend obtained in a study carried out in a hill district of eastern Nepal. Statistical significant associations was observed with sex of the child and risk of being wasted $(\mathrm{P}=0.04)$. $^{15}$
Inconsistent relation was observed between educational status of mother and wasting. The comparison of the same variables had a positive effective on wasting. With an increase of educational tier of mother, the prevalence rate declined. ${ }^{3}$ Significant association was observed with the age group of the children, compared to children of age one year of less, the children aged 13-35 months were at 6 times more risk of being wasted with $\mathrm{P}<0.05$ which is in line with the study at Dhankuta. Other factors those were found to be significantly associated with wasting in national and international studies were not significant in this study. ${ }^{15}$

More than $13 \%$ of under-five children of Bharatpur were under-weight compared to the national prevalence of $28.8 \%$. The prevalence of under-weight seems to be almost similar for male and female child; the findings are consistent with national figure. Comparison based on geographic, ecological and political area bases put the study area in stronger position with lower prevalence of under-weight. ${ }^{3}$ Finding are less than the study conducted in mid-western terai were 1 in 5, in Tanahun 27.1\% and in Dhankuta 27.3\% of the under-five children were under-weight. ${ }^{14-16}$

In this study families with less than 4 family members and 2 or less children were protective for under-weight and were statistically significant at $95 \% \mathrm{Cl}(\mathrm{P}=0.008$ and 0.002 respectively). Children from joint or extended families had 2 times higher odds of being under-weight. The probability of being under-weight was lowered with the increase in age which is consistent with the finding of Dhankuta. Mothers who smoked during their pregnancies had slightly higher chances of their child being under-weighted like finding of the study of Dhankuta. ${ }^{15}$ Children who had diarrheal episode (s) within 2 weeks period preceding the study were 2 times at more risk of being under-weight. Diarrhea was an associated characteristic as per the finding of the study from Banke. ${ }^{14}$ Similar extents of odds were obtained in the study of Dhankuta as well. ${ }^{15}$

Inconsistent results were obtained for the effects of socioeconomic status and educational status of mother for low weight-for-age. Several studies have shown the association between these variables. The study has found that the labor/service or business as occupation of mother was protective factor for under-weight. Occupation of the mother dichotomized as paid and unpaid had a significant association with under-weight of the children. ${ }^{14}$

More than a quarter (26.4\%) of under-five children of Bharatpur was found stunted in this study. The finding is too less than the national prevalence of stunting as pre NDHS 2011 is $40.5 \%$ but it is almost same as the prevalence of the problem for urban areas $(26.7 \%) .^{3}$ The prevalence of stunting found by similar studies in different parts of country were $18.6 \%$ at Banke, $36.7 \%$ at Dhankuta, $45.7 \%$ at Tanahu. ${ }^{14-16}$

\section{CONCLUSION}

Female child were found more vulnerable for malnutrition as compared to their male counterparts. Higher prevalence of underweight was seen following the increasing age of children. The size of family also matters the nutrition status 
of children. Children with episodes of diarrheal diseases had higher odds of having underweight. The overall findings of the study showed that there is an increased risk of under-nutrition among infants in comparison to more than one year old. This may be due to a combination of different interaction such as feeding practices and trends. Targeting mothers and educating them about health weaning practices may help to reduce the problem.

\section{RECOMMENDATIONS}

Malnutrition being an outcome of the various factors interplaying together requires a holistic model for approach. Factors such as nutrition intake, health issues, mother's nutritional status and environmental sanitation are few among the key players. Common childhood diseases control programs particularly CDD (Control of Diarrheal Disease) should take into account the nutritional aspect of the children in that period. Extra attention need to be taken to incorporate nutrition education in growth monitoring clinics from where mothers can get appropriate knowledge about their child's nutritional status and approaches by the Ministry of Health.

\section{REFERENCES}

1. World Health Organization. Dept. of Child and Adolescent Health and Development. Child and adolescent health and development progress report 2002-2003. Geneva: World Health Organization; 2004.

2. World Health Organization. The world health report: 2005: make every mother and child count: overview. Geneva: World Health Organization; 2005.

3. Nepal. Ministry of Health \& Population Division; New ERA (Firm: Kathmandu Nepal), Marco International. Nepal demographic and health survey, 2011. Kathmandu: Population Division, Ministry of Health and Population, Govt. of Nepal; 2012.

4. National Nutrition Policy and Strategy In: Nutrition Section, Child Health Division, Department of Health Services, editors. Kathmandu: Ministry of Health and Population; 2004.

5. Pelletier DL, Frongillo EA. Changes in child survival are strongly associated with changes in malnutrition in development countries. J Nutr. 2003 Jan; 133 (1): 107-19.

6. Lopez AD, Murray CC. The global burden of disease, 1990-2020. Nat Med. 1998 Nov; 4 (11): 1241-3.

7. Sah N. Determinants of Child Malnutrition in Nepal: A Case Analysis from Dhanusha, Central Terai of Nepal. Journal of Nepal Health Research Council. 2004; 2 (2): 50-5.

8. Nepal. Ministry of Health \& Population. Population Division, New ERA (Firm: Kathmandu Nepal), Macro International. Nepal demographic and health survey, 2006. Kathmandu: Population Division, Ministry of Health and Population, Govt. of Nepal; 2007.

\section{LIMITATION OF THE STUDY}

The study claims the result of nutritional status assessed by wasting, under-weight and stunting only on the basis of anthropometric measurements. Only selected factors in relation to child nutrition were included in the analysis. This study presents all forms of malnutrition which are the result of interplay of different factors and these factors most often do not occur in isolation. The occurrence of one may influence the occurrence of other. The under-weight of children is due the exposure of multiple factors.

\section{ACKNOWLEDGEMENTS}

We would like to acknowledge local FCHVs, mothers and their children who participated in this study.

\section{CONFLICT OF INTEREST}

We declare no conflict of interest.

9. World Health Organization. World health statistics 2007. Geneva: World Health Organization; 2007.

10. UNICEF. Progress for Children: A World Fit for Children Statistical Review. Geneva: UNICEF; 2007.

11. Mishra D, Singh HP. Kuppuswamy's Socioeconomic Status Scale - A Revision. Indian Journal of Pediatrics. 2003; 70.

12. Nutritional Survey Report Bardiya, Nepal. Kathmandu: Concern Worldwide 2008.

13. Nepal Multiple Indicator Surveillance (NMIS), Early Childhood Feeding, Nutrition and Development, Fourth Cycle. In: Central Bureau of Statistics, National Planning Commission, editors. Kathmandu 1997.

14. Acharya VP. Nutritional Status and Factors Affecting it among 6-59 months Children, Bhawanipur VDC of Banke district, Nepal. Kathmandu: Institute of Medicine, Tribhuvan University; 2011.

15. Sapkota VP. Prevalence and Predictors of Underweight, Stunting and Wasting among the Underfive Children in Belahara VDC of Dhankuta district, Nepal. Kathmandu: Institute of Medicine, Tribhuvan University; 2008.

16. Kumar N.S. Nutritional Status of Children Under-five Years and Women of Reproductive Age in Tanahun: Baseline Survey Report. Kathmandu: Nutrition Programme, UMN to Nepal 2003. 